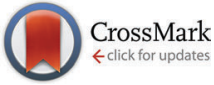

Cite this: Chem. Commun., 2016, 52,3970

Received 11th November 2015, Accepted 1st February 2016

DOI: $10.1039 / c 5 c c 09350 c$

www.rsc.org/chemcomm

The (de)lithiation process of carbon-coated $\mathrm{ZnFe}_{2} \mathrm{O}_{4}$ has been investigated by in situ Raman spectroscopy. Solid electrolyte interphase (SEI) products were detected. Their detection may result from a temporary surface enhancement Raman effect from Zn nanoparticles formed in the conversion reaction at a potential that coincides with SEI formation.

Lithium-ion batteries (LIBs) are electrochemical energy storage devices with a high energy density, as well as lightweight and flexible in design. In addition to being used in widely within the electronic device industry, power tools, and progressively automotive applications, they are being investigated as a large scale stationary storage technology. ${ }^{1,2}$ However, it is necessary that even greater improvements in terms of power, safety, lifetime, and cost of the LIB are achieved for stationary energy storage applications. ${ }^{1}$ The chemical stability and the lithium-ion conductivity are influenced by the passivation layers formed on the electrode surface of LIBs. In particular, the solid electrolyte interphase (SEI) is a multicomponent electron insulator film formed on the anode surface once in contact with the organicbased electrolyte, which has a great influence upon irreversible charge loss, power capability, cycle of life and safety. ${ }^{3}$ It consists of a patchwork of insoluble inorganic species and organic layers formed by non-aqueous electrolyte reduction products that prevent further electrolyte decomposition, but crucially still permit $\mathrm{Li}^{+}$ transport. ${ }^{3,4}$ Therefore, it is essential to understand the processes that occur at the electrode/electrolyte interfaces to improve the efficiency of LIBs.

${ }^{a}$ Stephenson Institute for Renewable Energy, Department of Chemistry, University of Liverpool, L69 7ZF, UK. E-mail: hardwick@liverpool.ac.uk

${ }^{b}$ Helmholtz Institute Ulm (HIU), Electrochemistry I, Helmholtzstrasse 11, 89081 Ulm, Germany

${ }^{c}$ Karlsruhe Institute of Technology (KIT), P.O. Box 3640, 76021 Karlsruhe, Germany

${ }^{d}$ Institute of Physical Chemistry, University of Muenster, Corrensstrasse 28/30,

48149 Muenster, Germany

$\dagger$ Electronic supplementary information (ESI) available: Experimental details and further in situ Raman investigation of $\mathrm{ZnFe}_{2} \mathrm{O}_{4}-\mathrm{C}$, uncoated $\mathrm{ZnFe}_{2} \mathrm{O}_{4}$ and $\mathrm{ZnO}-\mathrm{C}$, the Raman spectrum of $1 \mathrm{M} \mathrm{LiPF}_{6}$ in the EC/DMC electrolyte and the TEM image of $\mathrm{ZnFe}_{2} \mathrm{O}_{4}$-C. See DOI: 10.1039/c5cc09350c
$\mathrm{ZnFe}_{2} \mathrm{O}_{4}$ (ZFO) is a non-toxic and cheap anode material for LIBs with a high specific theoretical capacity of $c a .1000 \mathrm{~mA} \mathrm{~h} \mathrm{~g}^{-1,5,6}$ as a result of an alloying conversion reaction. ${ }^{7}$

$$
\begin{gathered}
\mathrm{ZnFe}_{2} \mathrm{O}_{4}+x \mathrm{Li}^{+}+x \mathrm{e}^{-} \rightarrow \mathrm{Li}_{x} \mathrm{ZnFe}_{2} \mathrm{O}_{4} \\
\mathrm{Li}_{x} \mathrm{ZnFe}_{2} \mathrm{O}_{4}+(8-x) \mathrm{Li}^{+}+(8-x) \mathrm{e}^{-} \rightarrow \mathrm{Zn}^{0}+2 \mathrm{Fe}^{0}+4 \mathrm{Li}_{2} \mathrm{O} \\
\mathrm{Zn}^{0}+\mathrm{Li}^{+}+\mathrm{e}^{-} \leftrightarrow \mathrm{LiZn} \\
\mathrm{Zn}^{0}+2 \mathrm{Fe}^{0}+4 \mathrm{Li}_{2} \mathrm{O} \leftrightarrow \mathrm{ZnO}+\mathrm{Fe}_{2} \mathrm{O}_{3}+8 \mathrm{Li}^{+}+8 \mathrm{e}^{-}
\end{gathered}
$$

Large volume changes during the (de)lithiation process as well as nanoparticle aggregation and poor intrinsic electronic conductivity lead to capacity fading and poor rate capability. ${ }^{6}$ These issues are overcome by encapsulating ZFO nanoparticles within a carbon matrix. A non-toxic, simple and environmentally friendly carbon coating of ZFO nanoparticles (ZFO-C) has been described by Bresser et al. ${ }^{5}$ In the present work, the ZFO-C composite during the first discharge-charge cycle is investigated by in situ Raman spectroscopy.

A spinel $\mathrm{ZnFe}_{2} \mathrm{O}_{4}$ material has five first order active Raman modes $\left(\mathrm{A}_{1 \mathrm{~g}}+\mathrm{E}_{\mathrm{g}}+3 \mathrm{~F}_{2 \mathrm{~g}}\right){ }^{8}$. The spectrum of the powder presents peaks at 340, 467, 647, 1098 and $1280 \mathrm{~cm}^{-1}$ (Fig. 1(i)). The peaks at 340 and $467 \mathrm{~cm}^{-1}$ are assigned to $2 \mathrm{~F}_{2 \mathrm{~g}}$ modes and $647 \mathrm{~cm}^{-1}$ is assigned to $\mathrm{A}_{1 \mathrm{~g}}$ symmetry. The other two modes at $221 \mathrm{~cm}^{-1}\left(\mathrm{~F}_{2 \mathrm{~g}}\right)$ and $246 \mathrm{~cm}^{-1}\left(\mathrm{E}_{\mathrm{g}}\right)$ are not observed clearly above the signal to noise ratio within the spectrum. The peaks observed at 1098 and $1280 \mathrm{~cm}^{-1}$ are suspected to be overtone bands.

$\mathrm{ZnFe}_{2} \mathrm{O}_{4}$ peaks are absent in the spectrum of the sample after the carbon coating step with a sucrose precursor (Fig. 1(ii)), which is in agreement with a previous report. ${ }^{9}$ Only two bands are observed at 1347 and $1586 \mathrm{~cm}^{-1}$ that are assigned to the characteristic carbon $\mathrm{D}$ and $\mathrm{G}$ bands, respectively. ${ }^{10,11}$ The $\mathrm{D}$ band $\left(\mathrm{A}_{1 \mathrm{~g}}\right.$ mode) results from a break in the symmetry at the edges or defects in graphene sheets. ${ }^{10-12}$ The $\mathrm{G}$ band assigned to the $\mathrm{E}_{2 \mathrm{~g} 2}$ mode is related to the $\mathrm{C}-\mathrm{C}$ stretching mode within the hexagonal lattice. ${ }^{10}$

The intensity ratio of the $\mathrm{D}$ and $\mathrm{G}$ peaks is sensitive to the type and order of the carbon material. ${ }^{11}$ In the present study, it is possible to distinguish the signal that corresponds to the 


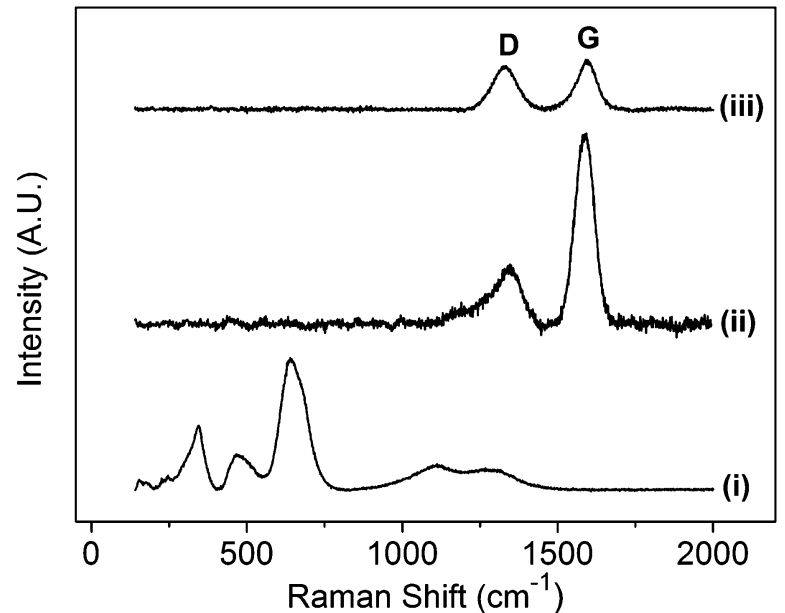

Fig. 1 Raman spectra of (i) uncoated ZFO; (ii) ZFO-C and (iii) carbon black (Super C65) powders.

carbon coating and that of the carbon additive (Fig. 1(iii)); the $\mathrm{D} / \mathrm{G}$ peak intensity ratio for ZFO-C and carbon black are 0.32 and 0.86 , respectively. Thereby, a clear differentiation between the two different types of carbon from Raman analysis of the composite electrode allowed precise monitoring of ZFO-C only rather than the carbon black conductive additive.

In situ Raman spectroscopy of ZFO-C film electrodes was performed in a three-electrode Raman cell containing $1 \mathrm{M} \mathrm{LiPF}_{6}$ in the $1: 1 \mathrm{w} / \mathrm{w}$ EC/DMC electrolyte. The electrode and cell preparations are described in the ESI. $\dagger$

The potential profile of the ZFO-C electrode during the first discharge-charge cycle is shown in Fig. 2. The maximum capacity at the end of the discharge process is $1221 \mathrm{~mA} \mathrm{~h} \mathrm{~g}^{-1}$ which is in agreement with previous studies and with the reactions described in eqn (1)-(3)., ${ }^{5,13}$ This value is similar to the capacity obtained for the uncoated ZFO film electrode (Fig. S1 in the ESI $\dagger$ ). The Raman spectrum collected at the open-circuit potential (OCP), shown in Fig. 3, presents peaks associated with

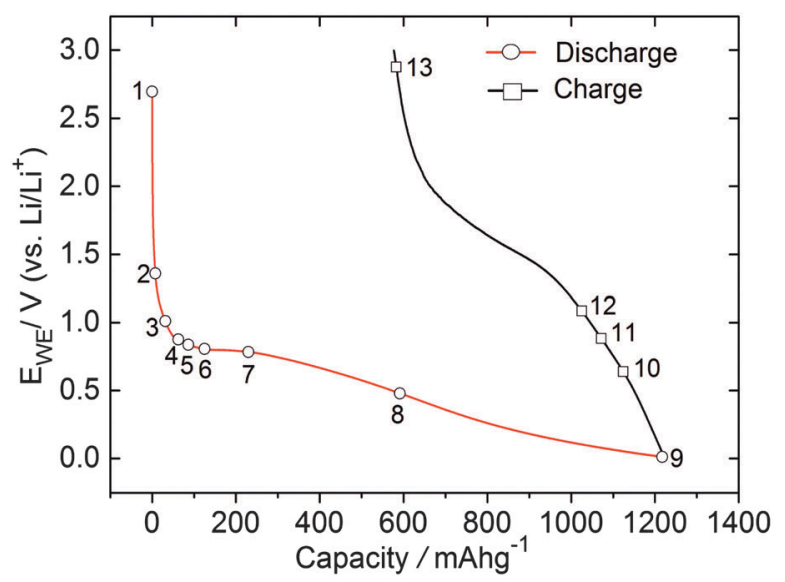

Fig. 2 Potential profile of the ZFO-C electrode for the first dischargecharge cycle in $1 \mathrm{M} \mathrm{LiPF}_{6}$ in the $1: 1 \mathrm{w} / \mathrm{w}$ EC/DMC electrolyte. In situ Raman spectra have been collected in the marked points at different stages of the discharge and charge processes.

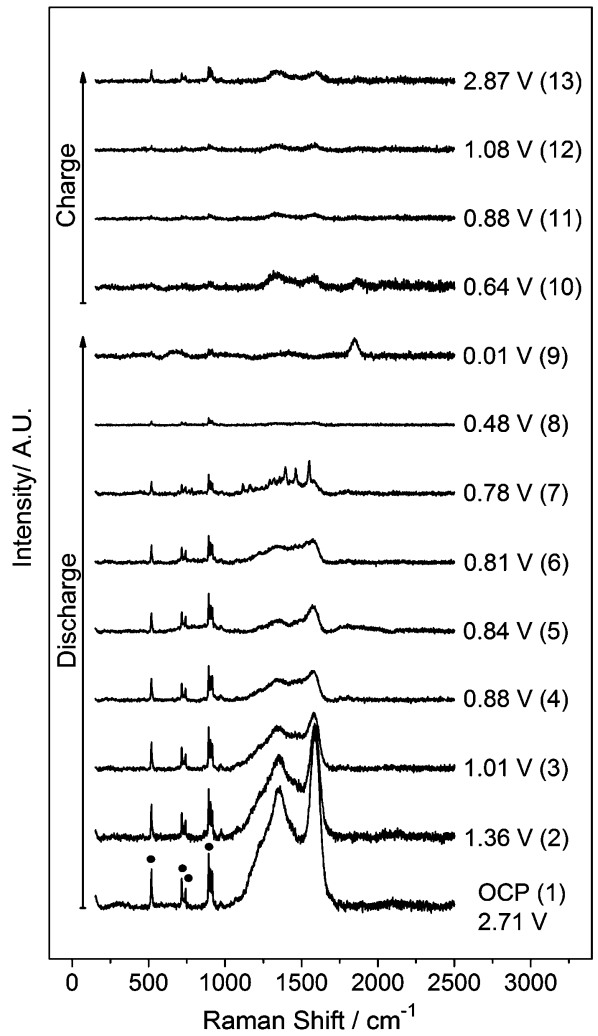

Fig. 3 In situ Raman spectra of the ZFO-C electrode collected at different stages of the discharge and charge cycles in $1 \mathrm{MLiPF}_{6}$ in the $1: 1 \mathrm{w} / \mathrm{w}$ EC/DMC electrolyte. Labels: $\bullet$ electrolyte peaks.

the electrolyte at 518, 717, 742, 893, 904 and $910 \mathrm{~cm}^{-1}$ (Fig. S2 in the ESI $\dagger),{ }^{14,15}$ in addition to D $\left(1347 \mathrm{~cm}^{-1}\right)$ and $\mathrm{G}\left(1590 \mathrm{~cm}^{-1}\right)$ peaks. Lithiation also occurs in the carbon coating, evidenced by the weakened $\mathrm{D}$ and $\mathrm{G}$ peaks, as the discharge reaction proceeds. These bands disappear into the background at potentials lower than $0.2 \mathrm{~V}$, and rise again during the charging of the cell at potentials above $0.64 \mathrm{~V}$ (spectrum 10) in agreement with previous reports for graphite. ${ }^{12}$ Raman data also highlight the fact that the carbon shell remains mechanically intact after the first discharge-charge cycle, as the ZFO band at $647 \mathrm{~cm}^{-1}$ is not observed after completion of the first de-lithiation step. A decrease in the peak intensity of the D and G bands is observed, when compared to the spectrum at OCP, suggesting that the de-lithiation step was not completely reversible and the part of lithium may still be trapped within the carbon shell. The $\mathrm{D} / \mathrm{G}$ intensity ratio is increased from 0.32 to 1.12 , thus the (de)lithiation steps result in an increase in the disorder of the carbon coating.

The conversion reaction described in eqn (2) occurs during the discharge plateau at around $0.80 \mathrm{~V}$ (see Fig. 2). ${ }^{7}$ This process leads to the destruction of the ZFO structure with the

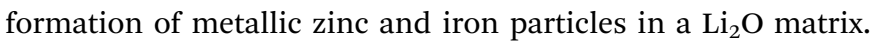
The zinc is then alloyed with lithium at more negative potentials (eqn (3)). ${ }^{7,16}$ Additional sharp peaks arise at 1118, 1163, 1292, 1319, 1357, 1395, 1463 and $1551 \mathrm{~cm}^{-1}$ in the Raman spectra collected between $0.80 \mathrm{~V}$ and $0.69 \mathrm{~V}$. These bands are related to the reduction products of the carbonate solvents that formed the SEI on the carbon coating as explained later in more detail. 
These peaks associated with the SEI products are absent in the spectra collected during in situ measurements of the uncoated ZFO electrode as shown in Fig. S1 (in the ESI $\dagger$ ). The explanation for this may be the different electrode/electrolyte interface, since the nanoparticles are not encapsulated in a carbon matrix. For ZFO-C only a band at approximately $1850 \mathrm{~cm}^{-1}$ is observed at potentials lower than $0.69 \mathrm{~V}$. A peak associated with $\mathrm{Li}_{2} \mathrm{C}_{2}$ has been previously reported at this wavenumber position. ${ }^{17,18}$ This peak is observed up to $0.64 \mathrm{~V}$ in the charge process, the potential at which the $\mathrm{D}$ and $\mathrm{G}$ bands re-appear in the spectra.

The SEI is comprised of organic and inorganic electrolyte decomposition products. ${ }^{4}$ Some of the organic compounds detected on carbon materials are lithium alkyl carbonate species $\left(\mathrm{ROCO}_{2} \mathrm{Li}\right)$ and polymeric species (e.g. polyethylene oxide). ${ }^{4,19}$

Polyethylene glycol/oxide powders with different molecular weights (PEG-1000, PEO-100k and PEO-1 M) have been studied by Raman spectroscopy to investigate the origin of the peaks observed during the discharge of the ZFO-C electrode between 0.80 and $0.69 \mathrm{~V}$ (Fig. 4). The peak analysis for PEO materials and the ZFO-C electrode at $0.78 \mathrm{~V}$ are presented in Table 1. There is a spectrum dependence on the chain length within the 800-1000 $\mathrm{cm}^{-1}$ region that corresponds to $\mathrm{CH}_{2}$ rocking and wagging coupled with $\mathrm{C}-\mathrm{O}, \mathrm{C}-\mathrm{C}$ and $\mathrm{C}-\mathrm{O}-\mathrm{C}$ stretching vibrations. ${ }^{20}$ The intensity of the peak at $840 \mathrm{~cm}^{-1}$ increases relative to the intensity of the band at $860 \mathrm{~cm}^{-1}$ as the average molecular weight increases. These peaks are related to the $\mathrm{CH}_{2}$ rocking and combined

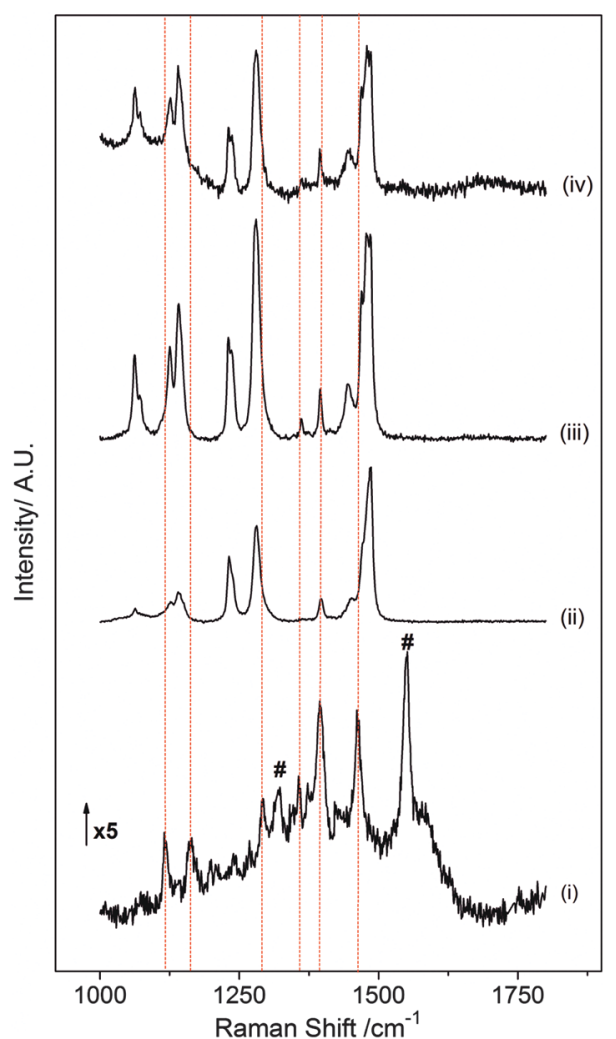

Fig. 4 Raman spectra of (i) the ZFO-C electrode discharged at $0.78 \mathrm{~V}$ and polyethylene oxide materials (ii) PEG (av. $M_{w}=1000$ ), (iii) PEO (av. $M_{w}=$ 100000 ) and (iv) PEO (av. $M_{\mathrm{w}}=1000000$ ).
Table 1 Raman peak position $\left(\mathrm{cm}^{-1}\right)$ and full-width at half maximum (FWHM $\mathrm{cm}^{-1}$ ) of polyethylene oxide compounds and for the ZFO-C electrode at $E=0.78 \mathrm{~V}$ during the discharge step

\begin{tabular}{|c|c|c|c|c|c|c|c|}
\hline \multicolumn{2}{|c|}{ PEG-1000 } & \multicolumn{2}{|c|}{ PEO-100 000} & \multicolumn{2}{|c|}{ PEO-1 000000} & \multicolumn{2}{|c|}{$\begin{array}{l}\text { ZFO-C electrode } \\
(\text { discharge } E=0.78 \mathrm{~V})\end{array}$} \\
\hline Peak & FWHM & Peak & FWHM & Peak & FWHM & Peak & FWHM \\
\hline $1125^{a}$ & 21 & $1125^{a}$ & 10 & $1125^{a}$ & 13 & 1118 & 7 \\
\hline - & - & $1142^{b}$ & 13 & $1142^{b}$ & 14 & 1163 & 10 \\
\hline $1281^{c}$ & 14 & $1280^{c}$ & 13 & $1281^{c}$ & 11 & 1292 & 9 \\
\hline - & - & 1361 & 6 & - & - & 1357 & 12 \\
\hline 1397 & 9 & 1395 & 5 & 1395 & 6 & 1395 & 14 \\
\hline $1476^{d}$ & 19 & $1445^{d}$ & 11 & $1445^{d}$ & 16 & 1463 & 13 \\
\hline
\end{tabular}

${ }^{a}$ Coupled $\mathrm{C}-\mathrm{C}$ stretching/ $\mathrm{CH}_{2}$ wagging. ${ }^{20}{ }^{b}$ Coupled $\mathrm{C}-\mathrm{C} / \mathrm{C}-\mathrm{O}-\mathrm{C}$ stretching. ${ }^{20}$ ${ }^{c}$ Twisting $\left(\mathrm{CH}_{2}\right)$ asymmetric. ${ }^{21} d$ Bending $\left(\mathrm{CH}_{2}\right)$ asymmetric. ${ }^{21}$

CO stretching/ $\mathrm{CH}_{2}$ rocking, respectively. ${ }^{20}$ There is a broadening in the spectrum background for PEO-1 M in the region from 700 to $1000 \mathrm{~cm}^{-1}$.

The spectrum collected at $0.78 \mathrm{~V}$ during the discharge cycle presents peaks at 1118, 1163, 1292, 1357, 1395 and $1463 \mathrm{~cm}^{-1}$ that can be related to PEG-PEO peaks at 1125, 1142, 1281, 1361, 1395 and $1445 \mathrm{~cm}^{-1}$. The peak shifts in the in situ spectra with respect to PEG-PEO powders could be explained by complexation with lithium cations in the electrolyte salt during cycling. The peak observed at $1357 \mathrm{~cm}^{-1}$ related to the PEO band at $1361 \mathrm{~cm}^{-1}$ is only present in the spectrum for PEO-100k, indicating that the polyethylene species formed on the electrode surface may have an average molecular weight in the order of $100 \mathrm{k}$.

One of the main peaks for polyethylene oxide materials appear at $1480 \mathrm{~cm}^{-1}$ with a shoulder at $1469 \mathrm{~cm}^{-1}$ assigned to the $\mathrm{CH}_{2}$ scissor mode. ${ }^{20}$ In the discharge curve only the shoulder is observed at $1461 \mathrm{~cm}^{-1}$. Two peaks at 1319 and $1551 \mathrm{~cm}^{-1}$ are not present in PEO materials (Fig. 4, \#). However, symmetric $\mathrm{C}=\mathrm{O}$ stretching in $\left(\mathrm{CH}_{2} \mathrm{OCO}_{2} \mathrm{Li}\right)_{2}$ and asymmetric $\mathrm{C}=\mathrm{O}$ mode for RCOOLi compounds have been reported in SEI studies using FTIR. ${ }^{4}$ Therefore, we tentatively assign these peaks to the lithium alkyl carbonate species that have been widely observed in previous SEI studies. ${ }^{4}$ These peaks have also been observed in the spectra collected on a ZFO-C particle when the potential was held at different potentials (chronoamperometric methods) as shown in Fig. S3 and S4 (in the ESI $\dagger$ ).

The conversion reaction in eqn (2) leads to the formation of zinc and iron nanoparticles. This reaction occurs approximately at $0.8 \mathrm{~V}^{7,16}$ The presence of $\mathrm{Zn}$ nanoparticles may enhance the Raman signal, explaining the observation of the peaks for the SEI components between 0.80 and $0.69 \mathrm{~V}$. The effect of $\mathrm{Zn}$ nanoparticles in surface-enhancement Raman scattering (SERS) has been described by Yang et al. in $\mathrm{TiO}_{2}$ nanoparticles doped with $\mathrm{Zn} .^{22}$ The disappearance of the peaks at potentials below $0.69 \mathrm{~V}$ could be explained by the formation of LiZn alloys in accordance with eqn (3) and/or the increase of the SEI thickness. This is schematically shown in Scheme 1. Di Cicco et al. have estimated the SEI thickness for the ZFO-C material using soft X-ray spectroscopy (XAS). ${ }^{13}$ In accordance with the thickness calculations as a function of the capacity, the SEI would be approximately $34 \mathrm{~nm}$ thick at $0.69 \mathrm{~V}$ and this thickness could inhibit the SERS effect. 


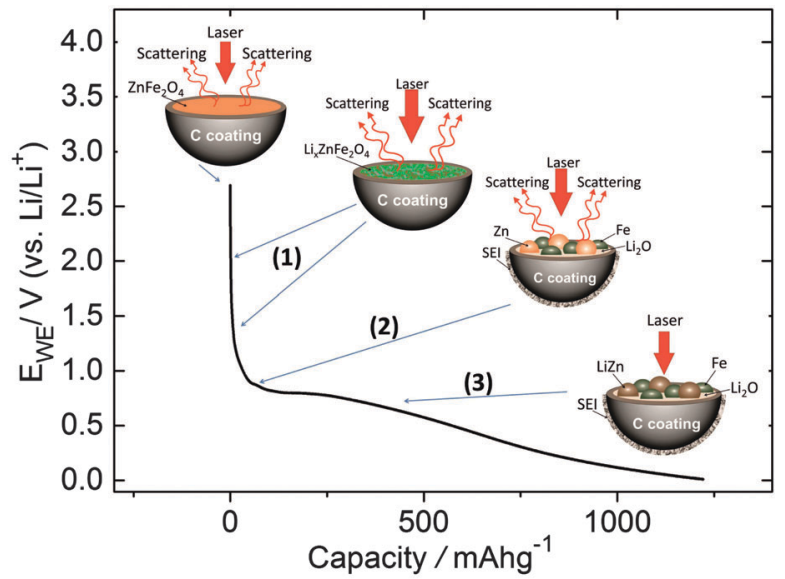

Scheme 1 Representation of the scattering phenomenon of ZFO-C during conversion-alloying reaction in the lithiation process at different potentials.

Although the active material is encapsulated inside a $2 \mathrm{~nm}$ carbon shell (Fig. S5 in ESI $\dagger$ ), the Raman enhancement by Zn nanoparticles is still observed. This phenomenon could be considered analogous to shell-isolated nanoparticle enhanced Raman spectroscopy (SHINERS). In this technique, the amplification of the signal is produced by gold nanoparticles with an ultrathin silica shell deposited on the substrate. ${ }^{23}$ Furthermore, a similar Raman enhancement showing PEO-type films has been observed on carbon-coated $\mathrm{ZnO}$ electrodes (Fig. S6 in the ESI $\dagger$ ).

In conclusion, carbon-coated ZFO has been investigated by in situ Raman spectroscopy during the first discharge-charge. The Raman spectrum of ZFO-C nanoparticles only presents the $\mathrm{D}$ and $\mathrm{G}$ bands related to the homogeneous carbon coating. The in situ Raman spectra show that the lithiation occurs not only in ZFO nanoparticles, but also in the carbon coating. As a consequence of this, the $\mathrm{D}$ and $\mathrm{G}$ bands disappear at potentials lower than $0.2 \mathrm{~V}$ and they re-appear during the charging step at potentials higher than $0.64 \mathrm{~V}$.

The carbon coating remains mechanically intact after the first cycle; however, the D and G peak intensity is lower, indicating that the de-lithiation is not fully reversible and lithium ions remain trapped in the carbon matrix. The $D / G$ intensity ratio is also larger, suggesting an increase in the disorder of the coating after the first (de)lithiation process.

SEI components on the carbon coating were assigned from the Raman data as the polyethylene oxide type and organic alkyl carbonate species. The observation of these compounds may be due to the SERS effect from the $\mathrm{Zn}$ nanoparticles formed from the conversion reaction during the lithiation process.

The support of the European Commission under the Project "Stable Interfaces for Rechargeable Batteries" (SIRBATT) (FP7-ENERGY-2013, grant agreement no. 608502) is gratefully acknowledged.

\section{Notes and references}

1 B. Dunn, H. Kamath and J.-M. Tarascon, Science, 2011, 334, 928-935.

2 J.-M. Tarascon and M. Armand, Nature, 2001, 414, 359-367.

3 E. Peled, J. Electrochem. Soc., 1979, 126, 2047-2051.

4 P. Verma, P. Maire and P. Novák, Electrochim. Acta, 2010, 55, 6332-6341.

5 D. Bresser, E. Paillard, R. Kloepsch, S. Krueger, M. Fiedler, R. Schmitz, D. Baither, M. Winter and S. Passerini, Adv. Energy Mater., 2013, 3, 513-523.

6 Y. Ding, Y. Yang and H. Shao, Electrochim. Acta, 2011, 56, 9433-9438.

7 A. S. Hameed, H. Bahiraei, M. V. Reddy, M. Z. Shoushtari, J. J. Vittal, C. K. Ong and B. V. R. Chowdari, ACS Appl. Mater. Interfaces, 2014, 6, 10744-10753.

8 Z. Wang, D. Schiferl, Y. Zhao and H. S. C. O'Neill, J. Phys. Chem. Solids, 2003, 64, 2517-2523.

9 F. Mueller, D. Bresser, E. Paillard, M. Winter and S. Passerini, J. Power Sources, 2013, 236, 87-94.

10 R. Baddour-Hadjean and J. P. Pereira-Ramos, Chem. Rev., 2010, 110, 1278-1319.

11 Y. Wang, D. C. Alsmeyer and R. L. McCreery, Chem. Mater., 1990, 2, 557-563.

12 C. Sole, N. E. Drewett and L. J. Hardwick, Faraday Discuss., 2014, 172, 223-237.

13 A. Di Cicco, A. Giglia, R. Gunnella, S. L. Koch, F. Mueller, F. Nobili, M. Pasqualini, S. Passerini, R. Tossici and A. Witkowska, Adv. Energy Mater., 2015, 5, DOI: 10.1002/aenm.201500642.

14 B. Fortunato, P. Mirone and G. Fini, Spectrochim. Acta, Part A, 1971, 27, 1917-1927.

15 J. E. Katon and M. D. Cohen, Can. J. Chem., 1975, 53, 1378-1386.

16 F. Martinez-Julian, A. Guerrero, M. Haro, J. Bisquert, D. Bresser, E. Paillard, S. Passerini and G. Garcia-Belmonte, J. Phys. Chem. C, 2014, 118, 6069-6076.

17 R. Schmitz, R. Ansgar Müller, R. Wilhelm Schmitz, C. Schreiner, M. Kunze, A. Lex-Balducci, S. Passerini and M. Winter, J. Power Sources, 2013, 233, 110-114.

18 R. Schmitz, R. Müller, S. Krüger, R. W. Schmitz, S. Nowak, S. Passerini, M. Winter and C. Schreiner, J. Power Sources, 2012, 217, 98-101.

19 A. M. Andersson, A. Henningson, H. Siegbahn, U. Jansson and K. Edström, J. Power Sources, 2003, 119-121, 522-527.

20 S. K. Chaurasia, R. K. Singh and S. Chandra, Vib. Spectrosc., 2013, 68, 190-195.

21 B. L. Papke, M. A. Ratner and D. F. Shriver, J. Phys. Chem. Solids, 1981, 42, 493-500.

22 L. B. Yang, Y. Zhang, W. D. Ruan, B. Zhao, W. Q. Xu and J. R. Lombardi, J. Raman Spectrosc., 2010, 41, 721-726.

23 J. Feng Li, Y. Fan Huang, Y. Ding, Z. Lin Yang, S. Bo Li, X. Shun Zhou, F. Ru Fan, W. Zhang, Z. You Zhou, D. Yin Wu, B. Ren, Z. Lin Wang and Z. Qun Tian, Nature, 2010, 464, 392-395. 